\title{
PROTOTIPE SISTEM KEAMANAN GARASI MOBIL UNTUK MENDETEKSI PERGERAKAN MENGGUNAKAN MIKROKONTROLER ATMEGA8535
}

\author{
Theresia Wuri Oktaviani \\ Fakultas Teknik, Jurusan Teknik Elektro \\ Universitas Cenderawasih Jayapura \\ Email: theresiawuri@gmail.com
}

\begin{abstract}
ABSTRAK
Temperatur merupakan salah satu ekspresi untuk energi kinetik dari pergerakan atom dan molekul. Jenis energi ini dapat diukur dengan berbagai fenomena antara lain perubahan volume, dapat diukur dengan berbagai fenomena antara lain perubahan volume, tekanan, resistansi, gaya elektromagnetik atau radiasi elektromagnetik. Passive Infrared (PIR) merupakan jenis radiasi pirometer untuk detektor foton. Radiasi yang datang akan menyebabkan detektor melepaskan sejumlah elektron dan menghasilkan sinyal listrik untuk digunakan dalam pengukuran. Passive Infrared (PIR) mendeteksi radiasi infra merah dari tubuh manusia yang sering digunakan dalam teknologi deteksi gerak. Detektor suhu yang digunakan hanya untuk mendeteksi orang yang bergerak tanpa adanya kemampuan untuk menghitung berapa banyak gerakan yang dilakukan oleh orang tersebut. Untuk menentukan jumlah gerakan orang maka sistem ini dibuat berbasis mikrokontroler ATMega8535. Apabila terdeteksi gerakan melebihi batas yang telah ditentukan maka sistem akan langsung bekerja. Metode yang digunakan dalam penelitian ini adalah dengan membuat perancangan sistem keamanan garasi mobil dan kemudian dilakukan pengujian berupa pengujian sistem mikrokontroler ATMega 8535, pengujian tampilan LCD 2x16, pengujian sensor PIR, dan pengujian sistem secara keseluruhan (pengujian berdasarkan jumlah gerakan dan pengujian lebar sudut pendeteksian sensor PIR). Dari penelitian diperoleh hasil yaitu semakin banyak jumlah gerakan yang ditangkap sensor, maka tegangan yang dihasilkan juga semakin besar. Buzzer dan LED akan menyala jika gerakan di atas 9 kali gerakan. Tegangan terbesar terjadi ketika sudut pengujian $0^{\circ}$ dan $90^{\circ}$. Buzzer dan LED menyala ketika sudut pengujian $0^{\circ}, 90^{\circ}$ dan $180^{\circ}$ atau dapat dikatakan pada saat posisi sejajar dan siku-siku.
\end{abstract}

Kata kunci: PIR, mikrokontroler ATMega8535, gerakan.

\begin{abstract}
Temperature is one expression for the kinetic energy of the movement of atoms and molecules. This type of energy can be measured by various phenomena such as volume change, can be measured by various phenomena such as volume change, pressure, resistance, electromagnetic force or electromagnetic radiation. Passive Infrared $(P I R)$ is a type of pyrometer radiation for photon detectors. The incoming radiation will cause the detector to release a number of electrons and generate an electrical signal for use in the measurement. Passive Infrared (PIR) detects infrared radiation from the human body often used in motion detection technology. The temperature detector is used only to detect the person moving without the ability to calculate how many movements the person performs. To determine the number of people movement then this system is made based mikrokontroler ATMega8535. If motion detection exceeds predetermined limits then the system will work immediately. The method used in this research is to make the design of car garage security system and then testing the form of microcontroller ATMega 8535 testing system, 2x16 LCD display testing, PIR sensor testing, and overall system testing (testing based on the number of motions and testing the wide angle of sensor detection PEAR). From the research results obtained that the more the number of motion captured sensor, then the resulting voltage is also greater. Buzzer and LED will light up if movement above 9 times movement. The largest voltage occurs when the test angle is $0^{\circ}$ and $90^{\circ}$. Buzzer and LED light up when the testing angle is $0^{\circ}, 90^{\circ}$ and $180^{\circ}$ or can be said at the time of parallel and right-angled position.
\end{abstract}

Keywords: PIR, microcontroller ATMega8535, movement.

\section{PENDAHULUAN}

Makin maraknya kasus pencurian kendaraan bermotor yang sering terjadi di kota Jayapura dan beberapa kota lainnya membuat pengguna kendaraan bermotor harus ekstra berhati-hati. Penelitian ini 
mencoba membuat sebuat prototipe yang bertujuan membantu pemilik kendaraan dalam hal keamanan di garasi dengan mengunakan mikrokontroler ATMega8535 yang berfungsi untuk mendeteksi pergerakan.

Passive Infrared (PIR) merupakan sebuah sensor yang bisa digunakan untuk mendeteksi pergerakan termasuk keberadaan manusia, biasanya digunakan untuk sistem alarm pada rumah atau perkantoran [1]. Proses kerja sensor ini yaitu dengan mendeteksi adanya radiasi panas suhu tubuh manusia yang kemudian diubah menjadi tegangan. Dengan memanfaatkan sensor ini maka penulis berharap dapat membantu memberi alternatif sistem keamanan kendaraan sehingga mengurangi resiko pencurian kendaraan bermotor. Penelitian ini hanya dibatasi oleh dua hal, yaitu cara kerja rangkaian meliputi rangkaian pada tiap blok serta fungsi masing-masing blok, dan sensitivitas sensor yang diatur dibatasi hingga kurang lebih 10 gerakan.

Telah dilakukan beberapa penelitian tentang sistem keamanan maupun tentang penggunaan mikrokontroler ATMega 8535, beberapa di antaranya yaitu Perancangan Sistem Keamanan Anti Pencuri Menggunakan Sensor PIR. Emma Naibaho. (2011) [2], Perancangan Pembuka Pintu Menggunakan AVR ATMega 8535. Yudi Andrian. (2009) [3], Sistem Pintu Otomatis dengan Sistem Pembacaan Kode Bar sebagai Kartu Identitas Berbasis Mikrokontroler AT89S51. Purnawarman Musa. (2008) [4], Pembuatan Kunci Elektrik. Ahmad Syaiful. (2004) [5], dan Pembuka Pintu Otomatis Menggunakan ATMega 8535 dan Sensor PIR. Raden Supriyanto (2010) [6].

\section{METODOLOGI PENELITIAN}

\subsection{Diagram Blok Rangkaian}

Diagram blok rangkaian dari alat sensor keamanan menggunakan PIR dapat dilihat pada Gambar 1. Sumber hanya menerima radiasi inframerah pada range panjang gelombang $(8-14 \mu \mathrm{m})$. Radiasi inframerah diubah dengan bentuk tegangan 5 Volt. Kemudian sensor PIR mendeteksi pergerakan manusia, apabila melewati ruangan maka akan diteruskan ke mikrokontroler. Pada mikrokontroler dianalisa pergerakan manusia yang diterima PIR, apabila pergerakan melebihi batas yang ditentukan pada ruangan tersebut, maka alarm aktif dan LCD menampilkan status.

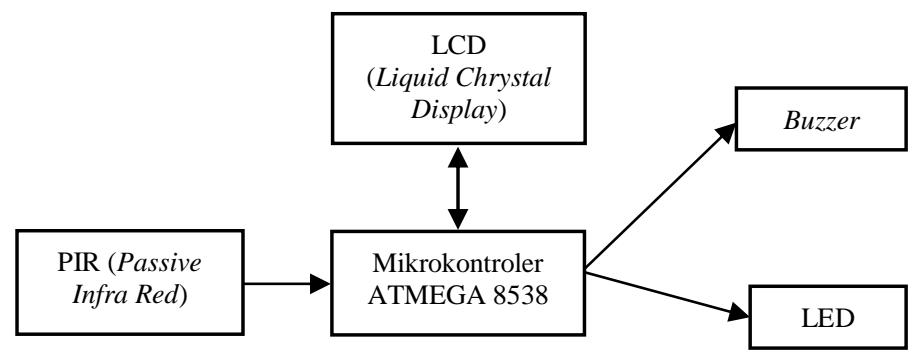

Gambar 1. Diagram Blok Rangkaian

\subsection{Sistem Minimum Mikrokontroler ATMega8535}

Rangkaian skematik dan layout PCB sistem minimum mikrokontroler ATMega8535 dapat dilihat pada gambar 2 .

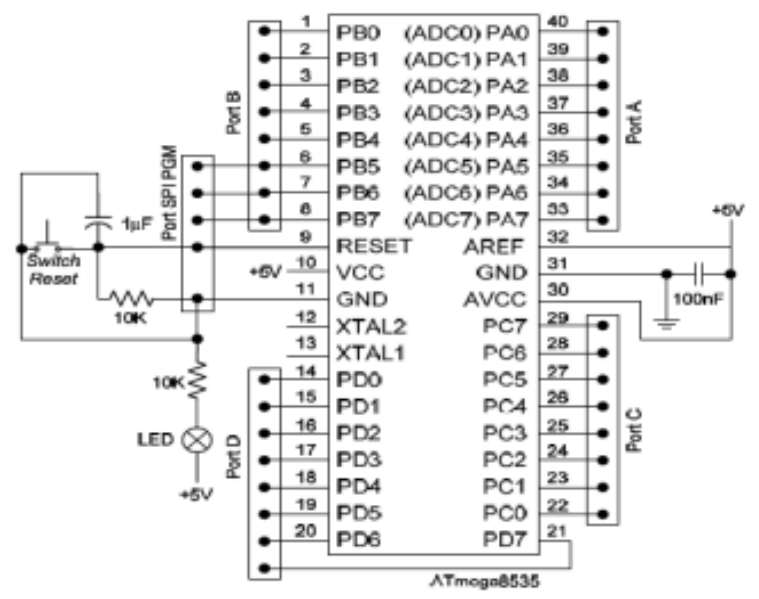

Gambar 2. Rangkaian Skematik Sistem Minimum Mikrokontroler Atmega8535 [6] 
Pin 18 dan 19 dihubungkan ke pin XTAL 11,0592 MHz dan dua buah kapasitor 30 pF. XTAL ini akan mempengaruhi kecepatan mikrokontroler ATMEGA 8535 dalam mengeksekusi setiap perintah dalam program. Pin 9 merupakan masukan reset (aktif tinggi). Pulsa transisi dari rendah ke tinggi akan mereset mikrokontroler ini. Pin 32 sampai 39 adalah Port 0 yang merupakan saluran/bus I/O 8 bit open collector dapat juga digunakan sebagai multipleks bus alamat rendah dan bus data selama adanya akses ke memori eksternal. Karena fungsi tersebut maka Port 0 dihubungkan ke resistor array. Jika mikrokontroler tidak menggunakan memori eksternal, maka penggunaan resistor array tidak begitu penting.

Selain digunakan untuk fungsi di atas resistor array digunakan sebagai pull up. Untuk men-download file heksadesimal ke mikrokontroler, Mosi, Miso, Sck, Reset, Vcc dan Gnd dari kaki mikrokontroler dihubungkan ke RJ45. RJ45 sebagai konektor yang akan dihubungkan ke ISP Programmer. Dari ISP Programmer inilah dihubungkan ke komputer melalui port paralel. Kaki Mosi, Miso, Sck, Reset, Vcc dan Gnd pada mikrokontroler terletak pada kaki 6, 7, 8, 9, 40 dan 20. Apabila terjadi keterbalikan pemasangan jalur ke ISP Programmer, maka pemrograman mikrokontroler tidak dapat dilakukan karena mikrokontroler tidak akan bisa merespon.

\subsection{Rangkaian LCD (Liquid Crystal Display)}

Rangkaian skematik konektor yang dihubungkan dari LCD (Liquid Crystal Display) ke mikrokontroler dapat dilihat pada gambar 3.

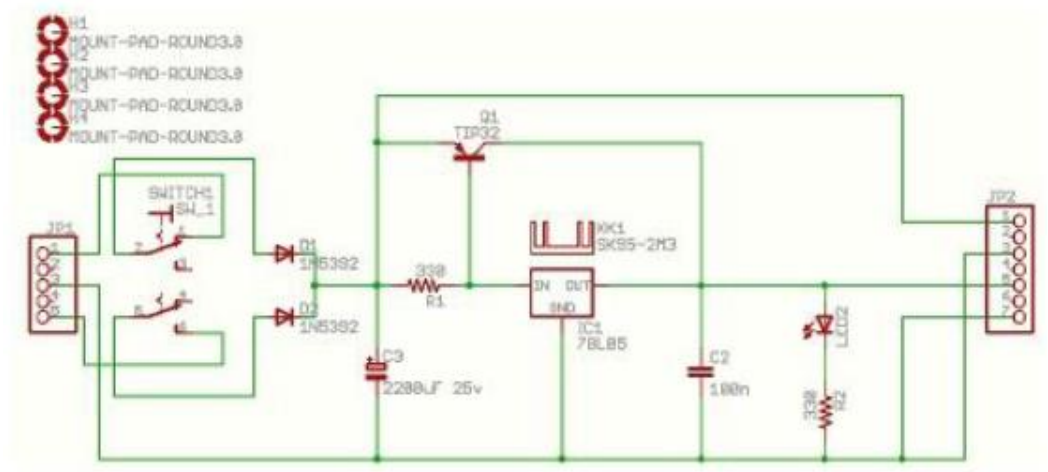

Gambar 3. Rangkaian Skematik Konektor Yang Dihubungkan Dari LCD Ke Mikrokontroler [7]

\subsection{Rangkaian Power Supply}

Rangkaian skematik power supply dapat dilihat pada gambar 4. berikut ini.

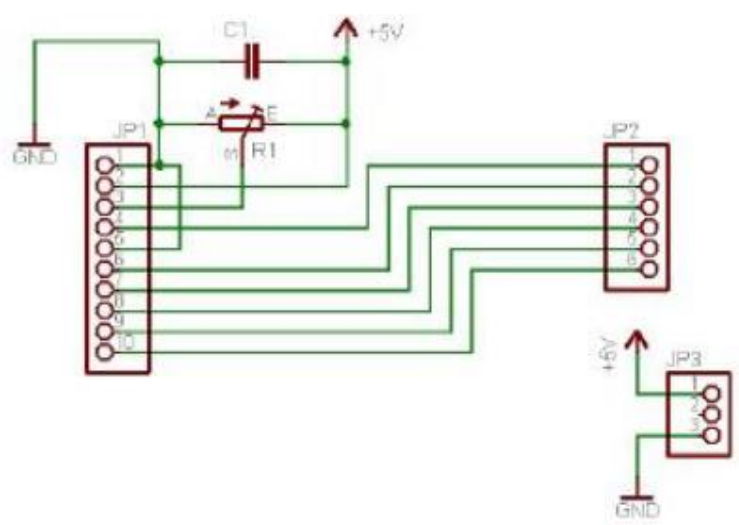

Gambar 4. Rangkaian Skematik Power Supply [7]

Rangkaian power suplly berfungsi untuk mensuplai arus dan tegangan ke seluruh rangkaian yang ada. Rangkaian power suplly ini terdiri dari dua keluaran, yaitu 5 Volt dan 12 Volt. Keluaran 5 Volt digunakan untuk menghidupkan seluruh rangkaian kecuali rangkaian ADC, sedangkan keluaran 12 Volt digunakan untuk mensuplai tegangan ke rangkaian ADC, karena rangkaian ADC memerlukan tegangan input sebesar 12 Volt agar tegangan referensinya stabil. Trafo stepdown yang berfungsi untuk menurunkan tegangan dari 220 Volt AC menjadi 12 Volt AC. Kemudian 12 Volt AC akan disearahkan dengan menggunakan dua buah dioda, selanjutnya 12 Volt DC akan diratakan oleh kapasitor $2200 \mu \mathrm{F}$. Regulator tegangan 5 Volt 
(LM7805CT) digunakan agar keluaran yang dihasilkan tetap 5 Volt walaupun terjadi perubahan pada tegangan masukannya. LED hanya sebagai indikator apabila PSA dinyalakan. Transistor PNP 32 disini berfungsi sebagai penguat arus apabila terjadi kekurangan arus pada rangkaian, sehingga regulator tegangan (LM7805CT) tidak akan panas ketika rangkaian butuh arus yang cukup besar. Tegangan 12 Volt DC langsung diambil dari keluaran jembatan dioda.

\subsection{Rangkaian PIR (Passive Infra Red)}

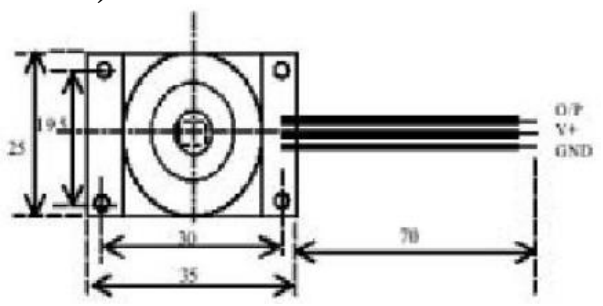

Gambar 5. Kaki Koneki PIR [8]

Tabel 1. Hubungan DT-51 dengan PIR

\begin{tabular}{cc}
\hline PIR Sensor & DT-51 MinSys Ver 3.0 Port Control \\
\hline OOP & Pin 4 (II) \\
$V^{+}$ & Pin 1 $($VCC) \\
$G N D$ & Pin 2 (GND) \\
\hline
\end{tabular}

Pada gambar di atas dapat dilihat bahwasannya PIR dihubungkan ke power supply melalui pin 1(Vcc) dan pin 2 (Gnd). Pada pin $3(\mathrm{O} / \mathrm{P})$ terkoneksi ke port pada mikrokontroler yang berfungsi sebagai counter yaitu port3.2.

\subsection{Flowchart Rangkaian}

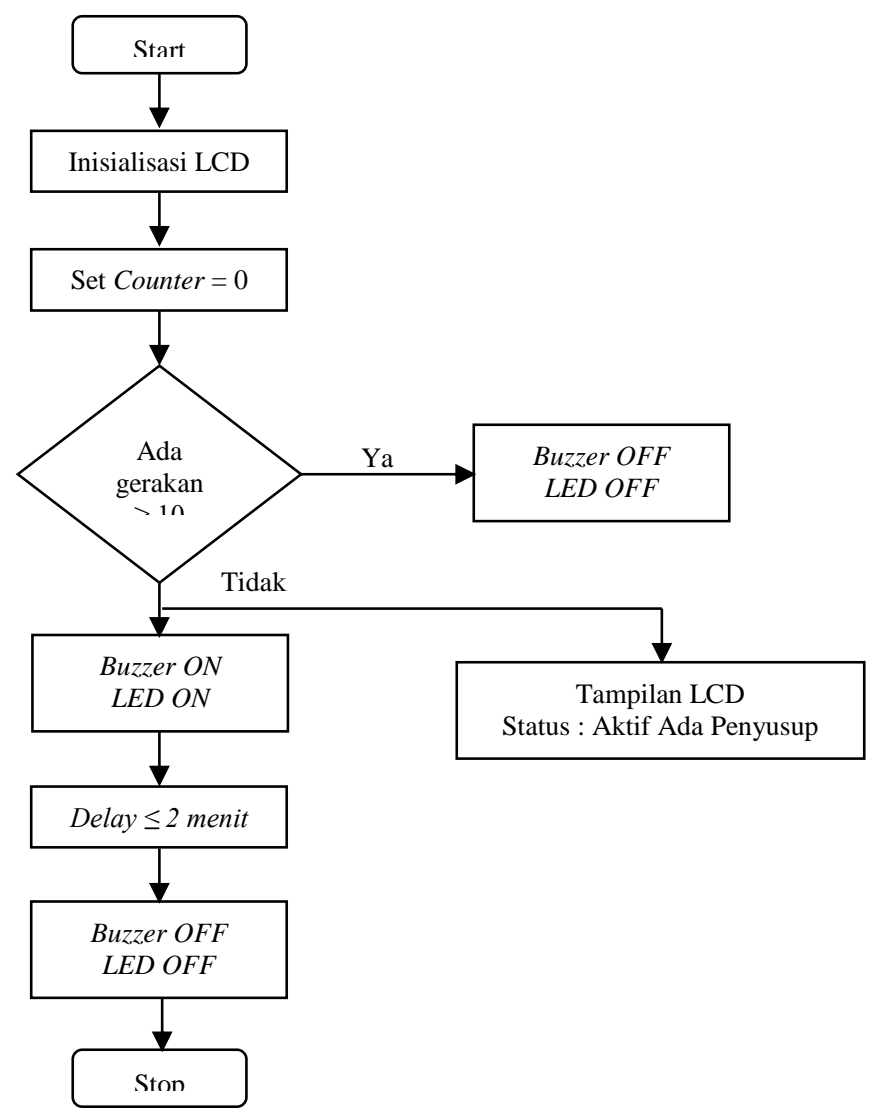

Gambar 6. Flowchart Rangkaian 
Keterangan flowchart :

a. Awalnya sistem akan menginisialisasi LCD dan mengeset counter menjadi 0 .

b. Kemudian sensor PIR mendeteksi apakah ada pergerakan, jika tidak sensor kembali mengecek.

c. Apabila sensor mendeteksi gerakan maka sistem akan menghidupkan buzzer sekali dan menampilkan "Sensor Aktif" pada LCD.

d. Setelah selang setengah detik sensor kembali mengecek apakah masih ada gerakan atau tidak jika tidak kembali ke prosedur awal.

e. Apabila masih terdeteksi gerakan lagi, maka counter terus menghitung sampai berapa kali gerakan berikutnya terdeteksi, jika belum sepuluh (10) kali terdeteksi maka buzzer hidup sekali dan kembali ke prosedur awal.

f. Apabila gerakan terdeteksi sepuluh (10) kali atau lebih maka buzzer akan hidup berkali-kali dan LCD menampilkan "Bahaya....." dan setelah beberapa saat sistem reset dan kembali mendeteksi.

\subsection{Rangkaian Pengkondisi Sinyal}

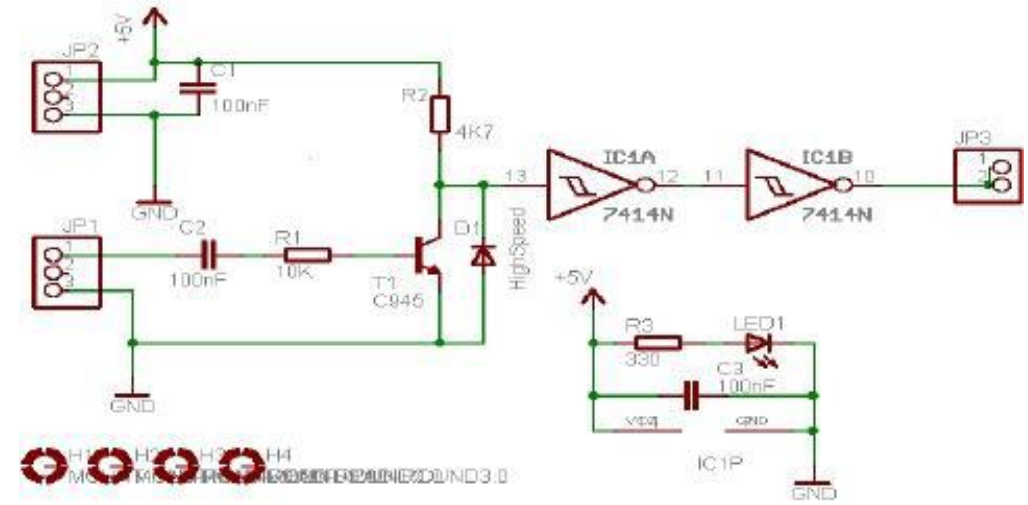

Gambar 7. Rangkaian Pengkondisi Sinyal [ 9]

\subsection{Data Sheet Sensor PIR}

\subsubsection{Umum}

KC7783 adalah suatu modul sensor pyroelectric yang dikembangkan untuk pendeteksian tubuh. Suatu PIR detektor dikombinasikan dengan sebuah lensa fresnel menjulang pada suatu ukuran ringkas PCB bersama-sama dengan suatu IC analog, KC778B dan membatasi pada komponen yang membentuk model tersebut. Keluaran lebar variabel tingkat tinggi adalah yang disajikan.

\subsubsection{Corak}

Ukuran ringkas $(25 \times 35 \mathrm{~mm})$, cakupan luas voltase operasi 4-12 V, keluaran khusus berdenyut lebar dapat diminta, TTL keluaran dapat secara langsung dihubungkan ke mikrokontroler atau alat logika, kepekaan tinggi, RFI imunitas tinggi, gerakan penundaan atas 25 detik.

\subsubsection{Spesifikasi Elektrik}

Operasi voltage 4-12 Volt, arus operasi $400 \mu \mathrm{A}$ pada $5 \mathrm{~V}$, PIR keuntungan masukan $68 \mathrm{Db}$, keluaran berdenyut lebar $0,5 \mathrm{det} / \mathrm{min}$, temperatur operasi $-20^{\circ} \mathrm{C}-50^{\circ} \mathrm{C}$. Dalam kaitan dengan kepekaan PIR alat sensor yang tinggi, itu bukanlah yang direkomendasikan untuk menggunakan modul itu di dalam yang berikut atau kondisi serupa.

a. Di dalam perubahan lingkungan cepat

b. Di dalam getaran atau goncangan kuat

c. Di dalam suatu tempat di mana ada sedang menghalangi material misalnya: gelas/kaca dengan mana IR tidak bisa lewat di dalam pendeteksian area.

d. Matahari langsung yang diunjukkan ke menyalakan/ menerangi

e. Angin langsung yang diunjukkan ke dari suatu alat pemanas atau alat pendingin. 


\subsection{Prinsip Kerja Sensor PIR}

PIR (Passive Infrared) merupakan sensor yang mendeteksi adanya pancaran sinar infra merah. Sensor PIR bersifat pasif, karena ia tidak memancarkan sinar infra merah tetapi hanya menerima radiasi sinar infra merah dari luar. Sensor ini biasanya digunakan dalam perancangan detektor gerakan berbasis PIR. Ketika sumber infra merah dengan suhu tertentu (ex : manusia) sensor akan membandingkan pancaran infra merah yang diterima setiap satuan waktu, sehingga ketika ada pergerakan maka akan terjadi perubahan pembacaan pada sensor ini. Bagian-bagian dari Sensor PIR yaitu :
a. Lensa Fresnel
b. Penyaring Infra Red
c. Sensor Pyroelektrick
d. Penguat Amplifier
e. Komparator

Pancara Infra merah masuk melaluilensa Fresnel dan mengenai sensor pyroelektrik, karena sinar infra merah mengandung energi panas maka sensor pyroelektik akan menghasilkan arus listrik. Sensor pyroelektrikterbuat dari bahan galium nitrida $(\mathrm{GaN})$, cesium nitrat (CsNo3) dan litium tantalate (LiTa03). Arus listrik inilah yang akan menimbulkan tegangan dan dibaca secara analog oleh sensor. Kemudian sinyal ini akan dikuatkan oleh penguat dan dibandingkan oleh komparator dengan tegangan referensi tertentu (keluaran berupa sinyal 1-bit). Jadi sensor PIR hanya akan mengeluarkan logika 0 dan 1, 0 saat sensor tidak mendeteksi dan 1 saat sensor mendeteksi. Sensor PIR didesain dan dirancang hanya mendeteksi pancaran infra merah dengan panjang gelombang 8-14 mikrometer. Diluar panjang gelombang tersebut sensor tidak akan mendeteksinya. Untuk manusia sendiri memiliki suhu badan yang apat menghasilkan pancaran infra merah dengan panjang gelombang antara 9-10 mikrometer (nilai standar 9,4 mikrometer), panjang gelombang tersebut dapat terdeteksi oleh sensor PIR. Pada umumnya sensor PIR memiliki jangkauan efektif hingga 5 meter.

\section{HASIL DAN PEMBAHASAN}

\subsection{Prototipe Sistem Keamanan Untuk Mendeteksi Pergerakan}

Berikut adalah hasil pengujian dari prototipe sistem kemanan berbasis mikrokontroler ATMega8535. Berdasarkan program perangkat lunak Proteus yang dapat dilihat dari hasil perancangan simulasi di bawah ini :

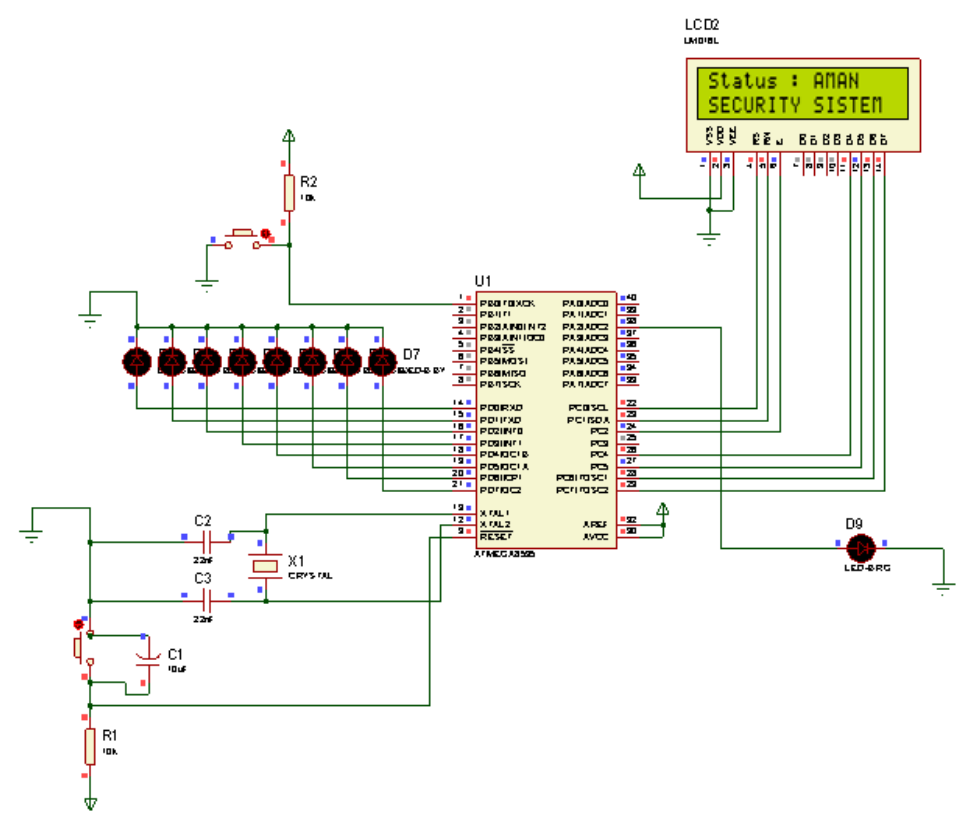

Gambar 8. Hasil Perancangan Sistem Keamanan Garasi Mobil 


\subsection{Pengujian Sistem Mikrokontroler ATMega8535}

ATMega8535 menggunakan kristal dengan frekuensi $4 \mathrm{MHz}$, apabila Chip Signature sudah dikenali dengan baik dan dalam waktu singkat, bisa dikatakan rangkaian mikrokontroler bekerja dengan baik dengan mode ISP-nya. Untuk mengetahui apakah rangkaian mikrokontroller ATMega8535 telah bekerja dengan baik, maka dilakukan pengujian. Pengujian bagian ini dilakukan dengan memberikan program sederhana pada mikrokontroler ATMega8535. Penggalan programnya menggunakan CodeVision AVR sebagai berikut :

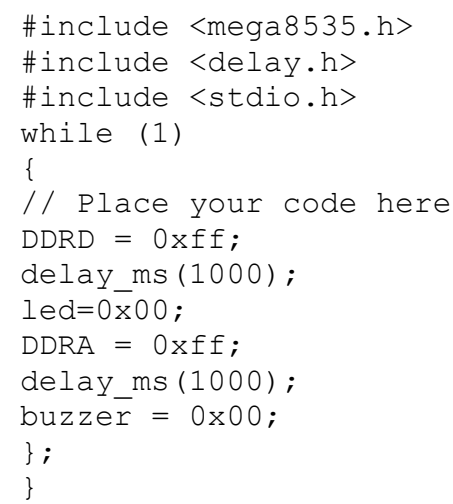

Program diatas bertujuan untuk menghidupkan LED yang terhubung ke Port D selama 1 detik dan mematikannya selama 1 detik secara terus menerus. Perintah DDRD=0xff memiliki logika high (1) yang berarti LED hidup dan perintah led=0x00 memiliki logika low (0) yang berarti mematikan LED selama 1 detik dengan perintah delay_ms(1000). Demikian pula untuk membunyikan buzzer yang terhubung ke Port A selama 1 detik dan mematikannya selama 1 detik secara terus menerus.

\subsection{Pengujian Tampilan LCD $2 \times 16$}

Pengujian modul LCD 2x16 dimaksudkan untuk mengecek tampilan LCD apakah tulisan atau karakter text yang kita inginkan dapat tampil pada LCD. Berikut penggalan programnya :

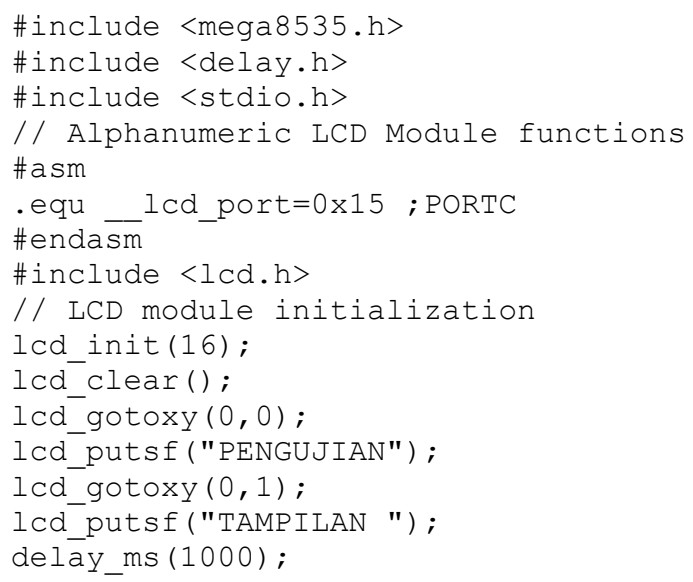

Berdasarkan program diatas tulisan "PENGUJIAN" ditampilkan pada baris pertama, sedangkan "TAMPILAN" akan ditampilkan pada baris kedua.

\subsection{Pengujian Sensor PIR}

Untuk keperluan security system sensor ini digunakan untuk mendeteksi adanya gerakan manusia di suatu ruangan atau area, sehingga sensor akan men-trigger alarm sistem bila ia mendeteksi kehadiran seseorang di ruangan tersebut. Perlu tidaknya ruangan yang ingin dimonitor oleh PIR harus benar-benar diperhitungkan. Berikut penggalan program utama menggunakan CodeVision AVR : 


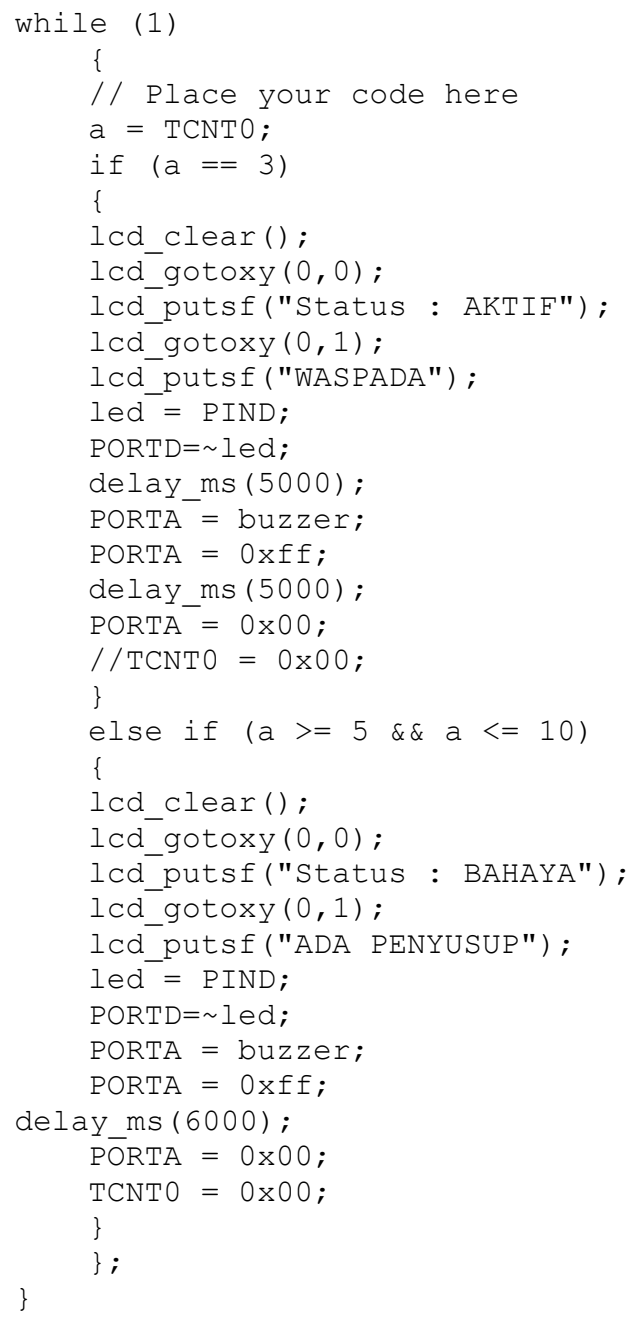

Berdasarkan program di atas, maka jika nilai ADC yang terbaca pada sensor sebesar 5V dengan set counter pergerakan kurang lebih 10 kali maka LED beserta buzzer akan ON secara bersamaan dengan tampilan LCD pada baris pertama "Status : BAHAYA" dan pada baris kedua dengan tampilan "ADA PENYUSUP" yang memberikan informasi kepada penghuni rumah akan kedatangan tamu yang tidak diundang, sedangkan apabila set counter kurang dari 10 kali pergerakan maka LED dan Buzzer dalam keadaan OFF dengan tampilan LCD pada baris pertama "Status : AKTIF" dan pada baris kedua "WASPADA" yang memberitahu penghuni rumah agar waspada, kemudian sistem kembali lagi mencacah dari awal dengan set counter $=0$.

\subsection{Pengujian Sistem Secara Keseluruhan}

Pengujian dilakukan dengan menghubungkan semua rangkaian, men-download software program kedalam mikrokontroler, selanjutnya melakukan pengukuran tegangan output pada sensor menggunakan AVO meter digital dan melihat tampilan nilai ADC pada display LCD.

\subsubsection{Pengujian Berdasarkan Jumlah Gerakan}

Pengujian ini bertujuan untuk mengetahui berapa kali jumlah gerakan yang akan dihitung oleh sensor untuk mengaktifkan buzzer dan LED serta menampikannya ke LCD. Pengujian dilakukan dengan cara menggerakan tangan di depan sensor dengan jarak yang berbeda-beda antara $40 \mathrm{~cm}$, pengambilan data berdasarkan indikator LED dan pengukuran besar tegangan DC yang dihasilkan sensor dengan multimeter. Hasil pengujian ditunjukkan pada tabel 2. 
Tabel 2. Tabel pengujian berdasarkan jumlah gerakan

\begin{tabular}{|c|c|c|c|c|c|}
\hline Pengujian & $\begin{array}{c}\text { Gerakan } \\
\quad(\text { kali })\end{array}$ & $\begin{array}{c}\text { Tampilan } \\
L C D\end{array}$ & $\begin{array}{c}\text { Tegangan } \\
(V)\end{array}$ & Buzzer & $L E D$ \\
\hline 1 & Fison & 0 & 1 & Off & Off \\
\hline 2 & 15: & 3 & 1,5 & Off & Off \\
\hline 3 & 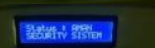 & 6 & 1,75 & Off & Off \\
\hline 4 & 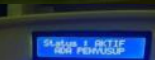 & 9 & 4,75 & On & On \\
\hline 5 & sus:- & 10 & 4,9 & On & On \\
\hline 6 & 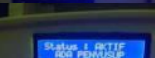 & 15 & 4,95 & On & On \\
\hline & cececese & & & & \\
\hline
\end{tabular}

Dari tabel 2 dapat dilihat bahwa dari enam kali pengujian didapatkan hasil semakin banyak gerakan maka tegangan yang dihasilkan juga semakibn besar, buzzer dan LED akan menyala ketika pergerakan sama dengan atau lebih dari 9 kali.

\subsubsection{Pengujian Lebar Sudut Pendeteksian Sensor PIR}

Pengujian ini bertujuan untuk mengetahui lebar sudut maksimal yang dapat dideteksi oleh sensor . Pengujian dilakukan dengan cara menggerakan tangan pada sudut-sudut tertentu antara $0^{\circ}$ sampai dengan $180^{\circ}$ dengan jarak $40 \mathrm{~cm}$ dari sensor, pengambilan data berdasarkan indikator LED dan pengukuran besar tegangan DC yang dihasilkan sensor dengan multimeter. Hasil pengujian ditunjukkan pada tabel 3.2.

Tabel 3. Pengujian lebar sudut pendeteksian sensor PIR

\begin{tabular}{|c|c|c|c|c|c|}
\hline Pengujian & $\begin{array}{c}\text { Sudut } \\
(*)\end{array}$ & $\begin{array}{c}\text { Tampilan } \\
\text { LCD }\end{array}$ & $\begin{array}{c}\text { Tegangan } \\
(V)\end{array}$ & Buzzer & LED \\
\hline 1 & 0 & 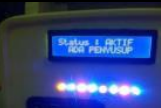 & 4,7 & On & On \\
\hline 2 & 30 & 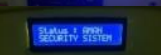 & 0,55 & Off & Off \\
\hline 3 & 90 & 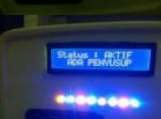 & 4,8 & On & On \\
\hline 4 & 120 & 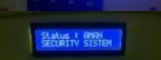 & 0,57 & Off & Off \\
\hline 5 & 180 & 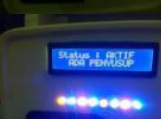 & 0,47 & On & On \\
\hline
\end{tabular}


Dari tabel 3 dapat dilihat bahwa tegangan terbesar terjadi pada sudut pengujian $0^{\circ}$ dan $90^{\circ}$. Buzzer dan LED menyala ketika sudut pengujian $0^{\circ}, 90^{\circ}$ dan $180^{\circ}$ atau dapat dikatakan pada saat posisi sejajar dan sikusiku.

\section{KESIMPULAN}

Dari hasil dan pembahasan, dapat diperoleh kesimpulan sebagai berikut:

a. Semakin banyak jumlah gerakan yang ditangkap sensor, maka tegangan yang dihasilkan juga semakin besar. Buzzer dan LED akan menyala jika gerakan di atas 9 kali gerakan.

b. Tegangan terbesar terjadi ketika sudut pengujian $0^{\circ}$ dan $90^{\circ}$. Buzzer dan LED menyala ketika sudut pengujian $0^{\circ}, 90^{\circ}$ dan $180^{\circ}$ atau dapat dikatakan pada saat posisi sejajar dan siku-siku.

\section{DAFTAR PUSTAKA}

[1] Carr, JJ., 1993. Sensor and Circuits: Sensors, tranducers, and supporting circuits for electronic instrumentation, measurement, and control, PTR Prentice Hall, New Jersey.

[2] Naibaho, Emma. 2011. "Perancangan Sistem Keamanan Anti Pencuri Menggunakan Sensor PIR". Publikasi Universitas Gunadarma Jakarta

[3] Andrian, Yudi dkk. 2009. "Perancangan Pembuka Pintu Menggunakan AVR ATMega 8535”. Jurnal STMIK Potensi Utama Medan

[4] Musa, Purnawarman dkk. 2008. "Sistem Pintu Otomatis dengan Sistem Pembacaan Kode Bar sebagai Kartu Identitas Berbasis Mikrokontroler AT89S51". PublikasiUniversitas Gunadarma Jakarta

[5] Syaiful, Ahmad. 2004. "Pembutan Kunci Elektrik". Publikasi Universitas Gunadarma Jakarta

[6] Supriyanto, Raden. 2010. "Pembuka Pintu Otomatis Menggunakan ATMega 8535 dan Sensor PIR", Publikasi Universitas Gunadarma Jakarta

[7] Datasheet Mikrokontroler AVR ATMega8535. http://www.atmel.com

[8] Datasheet LM35. http://www.sensirion.com

[9] Bejo, Agus., 2005. C\& AVR Rahasia Kemudahan Bahasa C dalam Mikrokontroler ATMega8535. Edisi Pertama. Yogyakarta: Penerbit Gava Media.

[10] Lingga, W., 2006. Belajar Sendiri Mikrokontroler AVR Seri ATMega 8535. Yogyakarta: CV. Andi Offset.

[11] Wasito, S., 1986. Kumpulan Data Penting Komponen Elektronika. Jakarta: PT. Multimedia 